\title{
Doctor Zhivago (David Lean, 1965): \\ la creación poética y su representación en el cine ${ }^{1}$
}

\author{
Doctor Zhivago (David Lean, 1965): \\ poetic creation and its representation in cinema
}

\author{
JUAN CARLOS PUEO \\ Instituto de Patrimonio y Humanidades \\ Universidad de Zaragoza \\ jcpueo@unizar.es \\ ORCID ID: 0000-0002-0761-2865
}

\begin{abstract}
Resumen: La adaptación cinematográfica de El doctor Zhivago se vio obligada a respetar la condición de poeta, muy relevante en la novela, del protagonista. No obstante, las digresiones sobre poesía hubieron de suprimirse para no lastrar el ritmo del relato, por lo que el director David Lean hace algunas alusiones a lo poético a partir del poder simbólico de la imagen para sugerir que la condición de poeta de Zhivago tiene un peso real.
\end{abstract}

Palabras clave: Doctor Zhivago, Borís Pasternak, David Lean, poesía.

\begin{abstract}
The film adaptation of Doctor Zhivago was forced to respect the poet's status, very relevant in the novel, of the protagonist. However, the digressions on poetry had to be suppressed in order not to weigh down the rhythm of the story, so director David Lean makes some allusions to the poetic based on the symbolic power of the image to suggest that Zhivago's status as a poet has a real weight.
\end{abstract}

Key Words: Doctor Zhivago, Borís Pasternak, David Lean, poetry.

\footnotetext{
${ }^{1}$ Este trabajo ha sido realizado en el marco del Grupo de Investigación de Referencia HERAF: Hermenéutica y Antropología Fenomenológica H05-17R de la Universidad de Zaragoza, financiado por el Gobierno de Aragón y el Fondo Europeo de Desarrollo Regional.
} 
El protagonista de la novela de Borís Leonídovich Pasternak El doctor Zhivago (1957), al igual que el de su casi inmediata versión cinematográfica, es presentado en el título de ambas como médico, dejando de lado la otra faceta del personaje, que es la que realmente le define: su condición de poeta y escritor. La profesión de Zhivago es la que le trae y le lleva por los escenarios por los que transcurre su peripecia vital, sobre todo en las dos ocasiones en que es movilizado para ir a la guerra como médico militar, pero esto no es lo que le define en el relato de Pasternak. Lo importante es la mirada que Zhivago proyecta sobre los escenarios que le rodean y los personajes que le acompañan. Mirada de poeta que traspasa la novela de un lirismo que la película de David Lean trató de llevar a la pantalla de forma discreta, teniendo en cuenta que lo que se pretendía hacer era, más que otra cosa, una historia de amor de dos personas de corazón sensible en los difíciles tiempos de la Revolución Soviética.

Pasternak señala en alguna ocasión que la forma que tiene Zhivago de practicar y enseñar la medicina no es nada ortodoxa, lo que provoca las reticencias, los celos y la enemistad de sus colegas, antes y después de la Revolución. Sus diagnósticos, realizados de forma intuitiva, y sus ideas, poco acordes con la racionalidad científica, le convierten en un profesional sospechoso, incluso a pesar de sus aciertos. El mismo Zhivago, al hablar de su forma de entender la medicina, le da ese toque de lirismo que le descubre como poeta, con los consiguientes recelos de sus colegas:

[...] Sin embargo, ellos gritan al unísono: «iQué genial diagnóstico, qué genial diagnóstico!». Y es cierto, raro es que yo me equivoque a la hora de determinar una enfermedad. Pero se trata justamente de esa intuición que ellos aborrecen y de la cual parece que yo peco, una comprensión íntegra que abarca todo el cuadro de golpe.

Estoy obsesionado con la cuestión del mimetismo, la adaptación externa de los organismos al color del ambiente que los rodea. Aquí, en esta adaptación cromática, se esconde la sorprendente transición del interior al exterior.

Me atreví a tocar este tema en mis clases. Y otra vez la misma cantinela: «Idealismo, mística. Filosofía goetheana de la naturaleza, neoschellingianismo» (Pasternak, 1957: 549-550).

No es desdeñable la alusión a Goethe y a Schelling, vinculados a un pensamiento idealista que pondría al sujeto por encima de cualquier otra instancia, ya que el subjetivismo es el gran pecado que la presunta ortodoxia marxista del Realismo Socialista reprochó a la «poesía burguesa». Sin necesidad de entrar en esta cuestión, valga el ejemplo 
para destacar lo poético de la mirada de Zhivago sobre la medicina ${ }^{2}$. Añádase a ello que las dificultades que surgen de esta mirada llevarán al doctor a abandonar su profesión, que solo retomará, de forma trágicamente irónica, el último día de su vida.

Mayor importancia tienen en la novela las ocasiones en las que se describen las ideas de Zhivago sobre poesía y arte, así como los momentos en que lleva a cabo su labor literaria. En la más ajustada tradición de la novela histórica, Pasternak propone un ejercicio narrativo sobre el efecto que ejercen en el protagonista los acontecimientos en que se vio inmersa Rusia en el primer tercio del siglo $\mathrm{XX}$, precisando que dicho protagonista es un poeta que proyecta su especial mirada tanto sobre lo personal -su biografía- como sobre lo colectivo -la historia-. De ahí que el narrador intervenga a menudo para dar a conocer la poética de Zhivago, que empieza a tomar forma ya desde su adolescencia:

Yura sabía pensar bien y escribir todavía mejor. Ya durante los años de colegio, soñaba con una obra en prosa, un libro autobiográfico en el que incluiría, como cargas explosivas ocultas, las cosas más sorprendentes que había visto y pensado. Pero era todavía demasiado joven para un libro semejante, así que se limitaba a escribir versos, como un pintor que durante toda su vida pinta estudios para el gran cuadro que tiene en la cabeza.

A esos versos Yura les perdonaba el pecado de haber nacido por su energía y originalidad. Yura juzgaba que esas dos cualidades, la energía y la originalidad, representaban la realidad en el arte, el cual era en todo lo demás abstracto, ocioso e inútil (Pasternak, 1957: 92).

Las ocasiones en que aparece en la narración la vocación literaria de Yuri Zhivago son bastante numerosas, culminando con una sección al final de la novela en la que se incluyen veinticinco poemas, sin especificar si se trata de la totalidad o de una antología ${ }^{3}$. En todas estas ocasiones puede asaltar al lector la tentación de identificar la poética de Yuri Zhivago con la de su creador, Borís Pasternak, reconocido

\footnotetext{
${ }^{2}$ De hecho, los estudios de medicina de Zhivago están fuertemente vinculados a su vocación poética. Al culminarlos con una tesis doctoral dedicada a los elementos nerviosos de la retina, se nos informa de que «ese interés por la fisiología de la vista revelaba otros aspectos de la naturaleza de Yura: las inclinaciones creativas y las reflexiones sobre la esencia de la imagen artística y la estructura del pensamiento lógico» (Pasternak, 1957: 110).

${ }^{3}$ Zhivago no es solo poeta: escribe también ensayos y artículos a los que se alude en algunos momentos de la narración, sin llegar a incluirlos en el apéndice final, además de un diario del que se reproducen algunos fragmentos.
} 
como uno de los principales poetas rusos del siglo Xx. Hay que tener en cuenta, sin embargo, que El doctor Zhivago no es un relato autobiográfico, y que las circunstancias vitales de Pasternak no fueron, ni mucho menos, las de su personaje. Pero tampoco es casual que la novela de un poeta narre las andanzas de un poeta. Hay una complicidad entre el autor y su personaje que permite ver el texto, entre otras muchas perspectivas posibles, como un testimonio acerca de las dificultades que suponía escribir cierto tipo de poesía en la Unión Soviética ${ }^{4}$. Una poesía en la que, a grandes rasgos, lo real aparece filtrado por la emoción individual de quien lo expresa, tal como se plantea escribir Zhivago tras el entierro de su madre adoptiva:

Yura caminaba solo, dejando rezagados a los otros con su paso veloz, y de vez en cuando se detenía a esperarlos. En respuesta a la desolación que la muerte había causado en aquel grupo de personas que marchaba lentamente a sus espaldas, con la imperiosidad con que el agua, retorciéndose por un embudo, se precipita hacia el fondo, él sentía el deseo de soñar y pensar, de trabajar sobre las formas, de producir belleza. Ahora más que nunca veía claro que el arte se ocupa siempre, sin interrupción, de dos cosas. Con insistencia reflexiona sobre la muerte y con insistencia, de ello, crea vida. El arte grande, auténtico, es aquel que se llama revelación de san Juan y aquel que sirve para completarlo.

Con anhelo, Yura saboreaba de antemano el momento en que desaparecería por dos o tres días del horizonte familiar y universitario y en que vertería, en los versos que escribiría a la memoria de Anna Ivánovna, todo lo que le pasaba en aquel instante, todo lo casual que la vida le ponía delante: dos o tres de los mejores rasgos distintivos de la difunta, la imagen de Tonia de luto; algunas observaciones hechas por la calle, en el camino de regreso del cementerio; la ropa lavada en aquel lugar donde, mucho tiempo antes, había aullado la tormenta y él, un niño, había llorado (Pasternak, 1957: 124-125).

Sin pretender agotar el tema de la poética de Zhivago y su posible vínculo con la de Pasternak - cabría incluso la posibilidad de considerar

\footnotetext{
${ }^{4} \ll$ Dr. Zhivago is above all the poetic biography of a richly endowed individual and the story of his unremitting efforts to maintain his creative integrity amid the overwhelming pressures of an age of wars and revolutions. True, Yury Andreyevich Zhivago cannot wholly be identified with Boris Pasternak: to confuse a literary character with its creator is always a dubious procedure. But the kinship between the two is not easily overestimated; and it is nowhere more apparent than in Zhivago's religious reverence for life and love, in his striving for absolute freshness of perception and the utmost directness of statement, and in his stubborn refusal to subordinate the dictates of his poetic vision to the ever-shifting demands of totalitarian bureaucracy» (Erlich, 1959: 335).
} 
a Zhivago un heterónimo, en la misma línea que los de Antonio Machado o Fernando Pessoa ${ }^{5}$, solo que ofrecido al lector como personaje novelesco, en todos los sentidos-, es preciso señalar que no son escasos los pasajes en los que la poesía o el arte se presentan como algo que se aprovecha de lo biográfico o de lo histórico para convertirse en una experiencia trascendente que, ciertamente, va más allá de la dinámica que pueda establecerse entre el creador y lo creado ${ }^{6}$, tal como escribe Zhivago en su diario:

Hace tiempo que estoy convencido de que el arte no es la denominación de una categoría o de un ámbito que comprende una cantidad ilimitada de conceptos y de fenómenos con sus ramificaciones, sino, al contrario, que es algo restringido, concentrado, la designación de un principio que integra la obra de arte, el nombre de la fuerza aplicada en ella o de la verdad que se ha trabajado. El arte nunca me ha parecido un objeto o un aspecto de la forma, sino más bien la parte misteriosa y oculta del contenido. Para mí está claro como la luz del día, lo siento con todas las fibras de mi ser, pero ¿cómo formular y expresar este pensamiento?

Las obras hablan de muy diversas formas: con los temas, las situaciones, las tramas y los personajes. Pero sobre todo hablan con la presencia de arte en ellas contenida. El arte presente en las páginas de Crimen y castigo trastorna más que el crimen de Raskólnikov.

El arte primitivo, el egipcio, el griego, el nuestro son, con toda probabilidad, en el transcurso de muchos milenios, una misma cosa, siempre arte en singular. Es una especie de pensamiento, de cierta afirmación de la vida, que por su amplitud lo abarca todo, no puede ser disgregado en palabras separadas y, cuando una pizca de esta

\footnotetext{
${ }^{5}$ No es una idea nueva: «Pasternak may be said to have invented Zhivago to go along with the poems. Pasternak both as man and as poet works through a mask, through -literally - the persona Zhivago, to whom he is tied more by the poems than by any biography or any history. Although Zhivago's poems contain images and thematic material linking them to Pasternak's other poetry, the poet's attitude is different» (Reeve, 1960: 124).

${ }^{6}$ Esta idea del arte haría, quizás, ociosa toda pretensión de precisar las posibles diferencias entre las respectivas poéticas de Pasternak y Zhivago, pues de lo que se trataría es de la capacidad del poeta, sea quien sea, para alcanzar esa experiencia estética trascendente y saber comunicarla a sus lectores: «By attributing his views and feelings to a fictional character, Pasternak makes a highly personal statement with an appearance of objectivity. He fashions a poet in his own image, and endows him with his own need to immortalize the significant moments of life. Pasternak is saying that the work of art survives the artist. The poems of the Appendix live on after the death of Zhivago as Pasternak's poetry and his Doctor Zhivago will live on after him» (Lamont, 1960: $621)$.
} 
fuerza integra cualquier compuesto más complejo, el aditivo del arte aumenta el significado de todo lo demás y se revela como la esencia, el alma y el fundamento de todo lo representado (Pasternak, 1957: 383).

La caracterización de Zhivago como poeta es, por tanto, asunto fundamental en la novela que no puede pasarse por alto - se ha dicho incluso que la narración no es sino el marco que sirve para exponer la colección de poemas que Pasternak había escrito previamente ${ }^{7}$. Aun así, la adaptación de El doctor Zhivago realizada por David Lean y el guionista Robert Bolt atiende a la cuestión de forma muy tangencial, lo que no puede extrañar a nadie si se tiene en cuenta que la perspectiva de Pasternak no tiene por qué coincidir con la de Lean, a quien le interesaba más la accidentada historia de amor de Yuri Zhivago (Omar Sharif) y Lara Antípova (Julie Christie) que la vocación poética del primero. De hecho, la poesía de Zhivago aparecerá supeditada casi siempre al melodrama, en una decisión consecuente con el trabajo de poda que guionista y director se vieron obligados a realizar respecto a la novela original para llevarla a la pantalla sin traicionar las líneas maestras de la narración ${ }^{8}$.

No obstante, la caracterización del protagonista tiene en cuenta su condición de poeta desde el primer momento. Ya en la primera secuencia, cuando el general Yevgrav Zhivago (Alec Guinness) nombra a su hermanastro Yuri lo hace sacando de su cartera un libro titulado Lara, de cuyo interior se ofrece un inserto (Fot. 1) que no deja lugar a dudas: la página derecha muestra un texto cuya disposición tipográfica indica que se trata, efectivamente, de un poemario. Con todo, es igualmente significativo que en la página izquierda aparezca el retrato de Lara, y que Yevgrav se refiera inmediatamente al libro dándole el título de Poemas a Lara, siguiendo la tradición poética que ha inducido a nombrar determinados conjuntos de poemas invocando a la amada del poeta, como ocurre con las Rime in vita e morte di Madonna Laura de Petrarca o los Sonnets pour Hélène de Ronsard. Hay que tener en cuenta

\footnotetext{
${ }^{7}$ «Pasternak wrote the novel as the frame of reference for the poem he wrote in the role of Zhivago. In this sense, the novel completes the poems, as it completes Pasternak's "own" poetry and his vision of reality. In this sense, the poems are the beginning of the novel» (Reeve, 1960: 129).

${ }^{8}$ «Tras un largo proceso en el que no faltaron discusiones, desacuerdos y enfrentamientos entre guionista y director, se dejó lista una adaptación de la obra de Pasternak, de la que se habían eliminado personajes, situaciones, matices. El guion definitivo daba un esencial protagonismo a la historia de amor del protagonista con Lara Antípova y reducía al máximo el trasfondo histórico y político de la narración» (Aparicio, 2008: 89).
} 
que la novela de Pasternak no da nombre al libro póstumo de Zhivago en ningún momento, que este recoge no solo textos poéticos, sino también artículos y ensayos, y que de los veinticinco poemas que forman la decimoséptima sección de la novela -titulada, sencillamente, Poesías de Yuri Zhivago-, tan solo nueve pueden leerse en clave amorosa, sin que en ninguno de ellos haya una referencia explícita al personaje de Lara. Cierto es que, en algunos casos, la referencia a Lara se deduce de la narración previa que permite al lector contextualizar el poema, pero tampoco es seguro que en el «tú»que aparece en otros textos - «La noche blanca», por ejemplo- haya de reconocerse necesariamente a Lara. Por lo demás, el narrador había indicado previamente que algunos de estos poemas, si acaso no todos, serían «olvidados luego, más tarde perdidos y nunca encontrados por nadie» (Pasternak, 1957: 586).

El poemario que aparece en esta primera secuencia es, pues, invención de los adaptadores, y no cabe duda de que si bien sirve para integrar en la caracterización de Zhivago su condición de poeta desde el primer momento, su función narrativa va más allá, pues tanto el título que nombra a Lara como la foto que acompaña a los poemas buscan sobre todo dejar claro el vínculo amoroso entre los dos personajes, caracterizándolos a la manera clásica como el poeta y su amada. Una caracterización nada inocente, dado que el imaginario colectivo considera que la pasión amorosa se sublima por medio del arte, en este caso la poesía. La historia de amor de Yuri y Lara que anticipa el poemario, y a la que Yevgrav añade algunos detalles como el nacimiento de una niña que sería fruto de su unión, no será una vulgar historia de amor como las demás, sino que vendrá avalada por la condición de los dos amantes: la de poeta y musa, respectivamente 9 .

El poeta Zhivago aparecerá en la película en pocas ocasiones más, sin que el tema de la poesía tenga otra función que la de destacar la

\footnotetext{
${ }^{9} \mathrm{Se}$ añade a todo ello algunos rasgos caracterizadores más: el ingeniero (Marc Eden) con quien está conversando Yevgrav declara ser lector devoto del poeta: «Nosotros admiramos mucho a su hermano», dice. Ese «nosotros» hace referencia a toda su generación, a la que Yevgrav acaba de aludir, y que seguramente ha tenido que leer a Zhivago de forma clandestina, dado que, tal como se nos informa inmediatamente, su obra ha estado prohibida por las autoridades soviéticas durante algún tiempo. A la condición de poeta apasionado hay que añadir, por tanto, la de portavoz de esa rebeldía juvenil que la propaganda antisoviética presentaba ya en los años sesenta como tímida reacción de las nuevas generaciones - siempre vigiladas y reprimidas- hacia las anquilosadas estructuras de poder de la URSS. Con todo, la prohibición de las poesías de Zhivago tampoco aparece en la novela de Pasternak.
} 
sensibilidad del personaje y su apasionado amor por Lara. Como ya se ha señalado, Pasternak se preocupa en su novela de exponer los procesos creativos que culminan en la escritura de los poemas que aparecerán en la sección final, lo que supone un grave problema para una adaptación que no puede dejar de tener en cuenta el hecho de que Zhivago atiende a su peripecia vital, por encima de todo, escribiendo. Así ocurre, por ejemplo, cuando una imagen sirve de estímulo poético para un par de versos que nacen de un primer chispazo de inspiración, pero que necesitan tomar forma por medio de un trabajo más concienzudo:

Estaban pasando por Kamerguerski. Yura dirigió su atención a una negra rendija que se iba abriendo en la costra de hielo de una de las ventanas. A través de la rendija se filtraba la luz de una vela, que penetraba en la calle casi con la conciencia de una mirada, como si estuviese espiando quién pasaba y esperase a alguien.

«Sobre la mesa ardía una vela, una vela ardía...», susurró Yura para sí el inicio de algo confuso, todavía informe, con la esperanza de que la continuación viniese por sí sola, sin esfuerzo. Pero no venía (Pasternak, 1957: 112-113).

Los versos aparecerán como estribillo del poema de la sección final «Una noche de invierno» (Pasternak, 1957: 715-716), haciendo ver al lector cómo lo que se manifestó en un momento en la forma de percepción estética de una circunstancia trivial acaba convirtiéndose en un texto poético complejo. Para el relato literario, esto resulta tan importante como la coincidencia que supone el hecho de que al otro lado de la ventana esté Lara -a la que Zhivago aún no conoce más que de vista- pidiéndole a su amigo Pasha que se case con ella. No es que el poema haga referencia a esta cuestión, puesto que no es posible que ninguno de los personajes pueda saber que esa vela que vio Zhivago al pasar por la calle una noche de febrero era la misma que iluminaba a Lara en ese instante decisivo de su vida. No obstante, el motivo de la vela tiene un carácter premonitorio que justificará a lo largo del relato el hecho de que Yuri y Lara se encuentren casi siempre por casualidad - uno de los reproches del que ha sido objeto la narración, tanto en su versión literaria como en su versión fílmica-.

Es esta premonición - al fin y al cabo, el espectador ya sabe desde que vio el libro Poemas a Lara que los dos personajes están destinados a encontrarse- la que destaca Lean al adaptar el episodio en su película. Las circunstancias son distintas, pues el filme aprovecha la ocasión para hacer que, en el interior de la casa, Lara confiese a Pasha (Tom Courtenay) la relación que ha mantenido previamente con Komarovski 
(Rod Steiger), lo que produce un efecto diferente en la narración ${ }^{10}$, ya que esta confesión ocurre en la novela más tarde. Aun así, la casual mirada de Zhivago a la ventana de Lara permanece: mientras Yuri y Tonia (Geraldine Chaplin) vuelven a casa en trineo, la mirada de él se dirige a la ventana iluminada (Fot. 2). Se destaca así el carácter premonitorio de la situación, pero sin atender a la inspiración poética que surge de ella, tal como observa Ramón Moreno Cantero:

[...] Lean conserva tanto la simultaneidad de ambas acciones como la observación de Yuri hacia esa ventana parcialmente opaca por el hielo que la empaña, aun separando unas existencias destinadas a caminar juntas. Cuando ese cristal se desempañe del todo, su transparencia contagiará a la narración, que al fin correrá fluida entre los destinos de ambos personajes [...]. El determinismo de Pasternak queda preservado por el de Lean, unidos, por una vez, en un mismo discurso; lo único relevante eximido del guion es el pensamiento de Yuri, acerca de un verso que le inspira la vela, pero que no acierta a terminar (Moreno Cantero, 2000: 47).

Esta omisión se lleva a cabo en aras de la economía del relato, que no puede detenerse en un poema que, en definitiva, aporta poco o nada a la narración. Lo cierto es que la mirada de Zhivago habría podido interpretarse - en un nuevo ejemplo de cómo funciona el efecto Kuleshov-como una mirada poética si el espectador estuviese al tanto de la inspiración que le llevará a escribir los versos citados por Pasternak. Sin embargo, ya he señalado que el poema «Una noche de invierno» no está vinculado a la historia de amor de Yuri y Lara, y es esto sin duda lo que lleva a Lean a prescindir de él en la construcción de esta secuencia.

${ }^{10}$ «El dolor entre Pasha y Lara al revelarle esta su aventura con Komarovsky es objeto de otra planificación silenciosa, separando la acción en sí con una ventana que a duras penas logra transparentarla entre el hielo derretido y la luz de una vela. En este caso, la suciedad visual - enormemente colorista- cubre la fotografía y lo que en ella sucede: en lugar del romanticismo, lo que surge del cristal es el lado turbio, convertido así en un elemento de doble función. Algo que Lean enfatiza cuando, en mitad de la escena, introduce el trineo de Tonia y Yuri pasando debajo de esa ventana: el doctor mira hacia arriba y solo ve una luz, dejando intuido que la admiración más propia de su tendencia al idealismo se ha apropiado del cristal que, para nosotros, significa algo muy diferente. Un cristal tan recio por su gruesa capa de hielo que bien podría materializar ese muro leaneano que nos separa de la experiencia estética impactante, que amortigua el contacto directo con la emoción pura» (Moreno Cantero, 1993: 284-285). 
La creación poética solo resulta relevante en la narración cinematográfica cuando resalta el período de plenitud absoluta de la relación amorosa de los dos personajes, el momento en que pueden alejarse de los vaivenes de los acontecimientos históricos para centrarse exclusivamente en su pasión. Es la ocasión, según la novela de Pasternak, para que Zhivago pueda dedicarse a escribir desde una situación de ideal aislamiento:

Y de nuevo, como en otro tiempo, Yuri Andréyevich se quedó petrificado, como clavado en el suelo, en el umbral del estudio, admirando su amplitud y sorprendiéndose de la anchura y la comodidad del escritorio junto a la ventana. Y de nuevo pensó que aquella austera comodidad disponía e invitaba a un trabajo paciente y fructifero (Pasternak, 1957: 578).

En efecto, Zhivago escribe. No solo mientras permanece con Lara en la finca de Varikino, sino también cuando ella ya se ha marchado con Komarovski. Pasternak narra el proceso de escritura atendiendo a todos los detalles que su propia experiencia como poeta le permite recrear, desde las sensaciones físicas que el personaje experimenta en ese momento hasta los impulsos inconscientes que vienen marcados por la naturaleza del lenguaje, pasando por el acto material de escribir a mano:

Un silencio plácido, colmado de felicidad y que exhalaba el soplo delicioso de la vida envolvía a Yuri Andréyevich. La lámpara derramaba una luz de un amarillo tranquilo que incidía sobre la blancura del papel y con un reflejo dorado nadaba sobre la superficie de la tinta dentro del frasco. Al otro lado de la ventana azuleaba la gélida noche invernal. Yuri Andréyevich fue a la habitación de al lado, fría y sin iluminar, desde la que se veía mejor el exterior, y miró por la ventana. La luz de luna llena ceñía la llanura nevada con una viscosidad que casi se podía tocar, de clara de huevo o albayalde. La paz llenaba el alma del doctor. Volvió a la habitación luminosa y bien caldeada y se puso a escribir.

Con una caligrafía amplia, procurando que el aspecto de lo que escribía transmitiese el vivo movimiento de la mano y no se desfigurase perdiendo el alma y enmudeciendo, recordó y escribió, con una redacción que poco a poco iba mejorando, alejándose de la forma inicial, los versos más definidos y memorables: «La estrella de Navidad», «Noche de invierno» y muchos otros poemas del mismo género, olvidados luego, más tarde perdidos y nunca encontrados por nadie.

Después pasó de estas cosas, asentadas y maduras en su interior, a otras que había iniciado y abandonado, aprehendió su tono y a vuelapluma bosquejó su continuación, sin la menor esperanza de 
darles término enseguida. Una vez se hubo lanzado, absorto en el trabajo, pasó a cosas nuevas.

Tras dos o tres estrofas que brotaron con facilidad y de varias comparaciones que a él mismo le sorprendieron, el trabajo se adueñó de él y sintió la proximidad de aquello que se llama inspiración. La correlación de fuerzas que rige la creación parecía tomar la iniciativa. La prioridad ya no la ostenta el autor ni el estado de ánimo que trata de expresar, sino la lengua con la que quiere expresarlo. La lengua, patria y receptáculo de la belleza y el sentido, comienza a pensar y a hablar por el individuo, y todo se convierte en música, no en el sentido de sonido exterior, sino en virtud de la impetuosidad y la potencia de su flujo interno. Entonces, como el inmenso torrente de un río que con su movimiento tornea las piedras del fondo y hace girar las ruedas de los molinos, el propio flujo del discurso, con la fuerza de sus leyes, crea en su camino, de paso, el metro y la rima, y otras mil formas y figuras, aún más importantes, pero desconocidas hasta ese momento, inexploradas, sin nombre.

En aquellos minutos, Yuri Andréyevich sentía que no era él quien ejecutaba la parte esencial del trabajo, sino algo que lo superaba, que se encontraba por encima de él y lo guiaba, a saber: el estado del pensamiento mundial y de la poesía, lo que a la poesía le estaba reservado en el porvenir, el siguiente paso que tendría que dar en su desarrollo histórico. Y él se sentía solo un pretexto, un punto de apoyo para que ella pudiera ponerse en movimiento (Pasternak, 1957: 585-587).

El progreso de la escritura poética se llevará a cabo en varios días, y Pasternak ofrecerá diversas perspectivas, desde la escritura serena que realiza su protagonista mientras convive con Lara hasta el enajenamiento que siente después de separarse de ella, que le lleva a adquirir «una contención interna que no le permitía poner demasiado en evidencia sus sentimientos personales y los acontecimientos reales» (Pasternak, 1957: 607). No es necesario poner más ejemplos, basta con dejar constancia de la importancia que tiene la creación literaria en este momento de la narración, que los adaptadores cinematográficos no pueden soslayar, sobre todo si recordamos que en la primera secuencia se había mostrado el libro Poemas a Lara, que aludía a esa sublimación de la pasión amorosa que va a alcanzar su momento álgido cuando los dos enamorados consigan aislarse del mundo.

¿Cómo representar, sin embargo, la inspiración poética que describe Pasternak en su novela? Entre la imagen que muestra a Zhivago meditando antes de ponerse a escribir a la luz de una vela, y la que poco después ofrece el fruto de su trabajo - con la vela ya consumida- media una elipsis que suprime todas las consideraciones que había planteado la novela en torno a la creatividad del protagonista 
y su manera de enfocar la tarea de la escritura. Evidentemente, hay hojas de papel estrujadas, rasgadas, emborronadas y tachadas que hablan de un proceso complejo que comenzaría con una primera redacción, imprecisa y titubeante, y que proseguiría con diferentes correcciones hasta alcanzar su estado definitivo. Sin embargo, todo eso ha quedado elidido. Ni siquiera se da al espectador la oportunidad de conocer el resultado, cuya calidad solo conocemos a través de la emocionada lectura que realiza Lara a la mañana siguiente.

Con esta elipsis, debemos entender que Lean renuncia a expresar los complejos mecanismos de la creación literaria expuestos por Pasternak, ya que lo único que se ofrece al espectador es el momento en que Zhivago se dispone a trabajar y el resultado final de su trabajo, pero no el trabajo de escritura en sí. Se hace preciso aducir, una vez más, que la economía narrativa no hubiera soportado, tanto en lo referido a la duración de la película como a su ritmo, una digresión sobre la escritura poética como las que se permite el novelista.

Ahora bien, las circunstancias que rodean la creación poética no quedan silenciadas del todo. Lean lleva a sus personajes a un espacio particular, el de la finca campestre de Varikino, que presenta de forma completamente distinta a como han aparecido los demás espacios del relato. Se trata de un espacio simbólico, un palacete nevado tanto en su exterior (Fot. 3) como en su interior (Fot. 4) y dotado de un aura de irrealidad y de magia ${ }^{11}$ que el espectador no tarda en apreciar como espacio propicio a actividades tan extraordinarias como la creación poética:

[...] el diseño de la mansión constituye un acierto evidente, inexistente en la novela. La casa está completamente cubierta de nieve por fuera y permanece congelada por dentro: no cabe mejor visualización de lo que los amantes pretenden, esto es, la preservación de su vida común, a refugio de un mundo que los ha colocado en su punto de mira, ámbito fortificado por un doble amurallamiento blanco y cuyo frío interior parece hecho para conservar. Zhivago entra, y en su recorrido va personalizando dicho interior, hasta llegar al gran escritorio en el que aprendió a escribir durante su infancia:

\footnotetext{
${ }^{11}$ En el documental Doctor Zhivago. The Making of a Russian Epic, el diseñador de la producción, John Box, recordaba que era esa sensación precisamente la que quería producir: «Muy emocionante. Estos dos personajes regresan allí y entran. ¿Qué van a encontrar? No sabía qué hacer y vi una imagen de los últimos días de Scott en la Antártida en la habitación. Había un agujero y el viento soplaba nieve a través de él. Se habían formado figuras extrañas. Eso me dio la idea. Coge el decorado, que es algo irreal y real a la vez, y cúbrelo de hielo» (Benson, 1995: 32.05-32.40).
} 
mesa que volverá a utilizar para retomar su inspiración poética. Intuimos así que este ámbito, solitario y privado, será también lugar de creación artística: y para que lo sea, su iconicidad fílmica ha optado sin vacilar por la irrealidad, noción equivalente a la del refugio intemporal que pretenden obtener en medio de una tormenta imposible de evitar (Moreno Cantero, 2000: 72).

No cabe duda de que este espacio maravilloso tiene la función de alojar la escritura poética, que es en sí misma algo «mágico», genial e inspirada expresión de lo que, por lo general, se percibe como inexpresable. Esta presencia de lo simbólico no es ajena a la novela de Pasternak, también en el episodio de Varikino. Los lobos que interrumpen con sus aullidos la escritura de Zhivago aluden con toda claridad a los peligros que amenazan a los dos amantes en el mundo exterior. El poeta se ve obligado a salir de su estado de inspiración para echar un vistazo fuera de la casa, hasta que los lobos salen huyendo, acción que Lean recoge en el filme, añadiendo además el gesto que realiza Zhivago para espantar a los lobos, con el que subraya la voluntad del protagonista de sustraerse de las imposiciones provenientes del exterior. Es importante tener en cuenta el significado simbólico de estos lobos para relacionarlo con el siguiente objeto que atrapa la mirada del poeta, que no es otro que la vela que ilumina la estancia en la que ha estado trabajando (Fot. 5), y que él ve desde el exterior.

No se trata solo de enfatizar la calidez e iluminación del interior frente al frío y oscuridad del amenazante exterior. Lo curioso del caso es que esta mirada de Zhivago, tan similar a la que ya habíamos visto en el episodio moscovita de la calle Kamerguerski, no aparece en la novela de Pasternak, sino que es producto de la intervención de David Lean, junto con el guionista Robert Bolt y el diseñador de producción John Box, que recogen la sugestión poética silenciada en dicho episodio para colocarla allí donde la creación poética tiene verdadera relevancia para el relato. Obsérvese que la luz resplandece rodeada por los caprichosos dibujos que el hielo ha formado en el cristal de la ventana, vinculados a la mágica ambientación del palacio nevado donde tiene lugar la escritura poética de Zhivago. Y tampoco se pueden olvidar las connotaciones simbólicas asociadas a la imagen de la vela, tal como las explica Gaston Bachelard en su sagaz ensayo sobre La llama de una vela:

Entre todas las imágenes, las imágenes de la llama -tanto las ingenuas como las alambicadas, las prudentes como las locasostentan el signo de la poesía. Todo soñador de llama es un poeta en potencia. Todo ensueño frente a una llama es un ensueño admirable. Todo soñador de llama se encuentra en un estado de ensoñación primordial. Esa admiración primordial hunde sus raíces en un pasado 
lejano. La llama nos provoca una admiración natural, una admiración innata, nos atreveríamos a decir. La llama implica una agudización del gusto de mirar, un más allá de lo ya visto. Nos obliga a mirar (Bachelard, 1961: 8).

No es extraño, por tanto, que la imagen que sigue a la de la vela desde el exterior vuelva a mostrar el escritorio donde Zhivago se dispone a escribir un poema, sobriamente dispuesto con los útiles de escribir - papel, tintero, pluma- y esa vela que, indiscutiblemente, hay que relacionar con la inspiración poética. Para el doctor Zhivago de David Lean, la poesía es el espacio mágico donde puede concentrarse en su amor por Lara - los cuatro caracteres del alfabeto cirílico que componen su nombre son lo único que el espectador ve escribir a Yuri- y dejar de lado los peligros que para esta relación amorosa supone la agitación del mundo exterior, el proceso histórico de la Revolución Soviética que, según preconizaba la propaganda antisoviética en los años de la Guerra Fría, acabaría arrasando con todo lo que se le pusiera por delante para imponer su orden igualitario sobre la libertad individual.

Las connotaciones simbólicas que relacionan la llama de la vela con el espíritu de la poesía tampoco son ajenas a la novela de Pasternak. Es evidente que estaban ahí, en el episodio de la calle Kamerguerski y en el primer chispazo de inspiración que llevaría a Zhivago a componer más tarde el poema «Una noche de invierno» ${ }^{12}$. Lo están igualmente en el la decimocuarta parte, dedicada a la estancia de Yuri y Lara en Varikino, aunque de otro modo, ya que la luz de la vela no consigue que el poeta se olvide de los peligros que le amenazan:

La lámpara alumbraba con una luz viva y acogedora, como antes. Pero no pudo escribir más. No conseguía serenarse. No pensaba sino en los lobos y otras dificultades amenazantes. Además estaba cansado. En aquel momento se despertó Lara:

- Ardes y das calor siempre, mi querida velita! - dijo en un suave susurro, húmedo y lleno de sueño--. Siéntate un momento aquí a mi lado, muy cerca. Te contaré el sueño que he tenido.

Y apagó la lámpara (Pasternak, 1957: 588).

\footnotetext{
${ }^{12}$ Es posible que en un estadio inicial del guion se incluyese alguna referencia a esa inspiración poética, lo que explicaría la mirada que Zhivago dirige a esa vela mientras pasea en trineo con Tonia, mirada que ya no sería entonces una simple premonición de su relación sentimental con Lara, sino algo más complejo, en el que podría incluirse el papel que juega la poesía como exaltación sublimadora del sentimiento amoroso. Lamentablemente, no es posible - al menos, por ahora-salir en esta cuestión de lo meramente especulativo.
} 
La acción de Lara al apagar la lámpara, habiendo caracterizado antes al poeta como «mi querida velita», supone la desconexión de la inspiración poética a la que Pasternak había dedicado el capítulo, terminándolo ahí, en el momento en que los dos amantes se abrazan. Zhivago ya no escribirá más esa noche, y al día siguiente tendrá que dedicarse a otras labores más prosaicas como llevar leña a la casa o ayudar a Lara en otras tareas domésticas. En la película, en cambio, la luz de la vela brilla resplandeciente, y Zhivago prosigue con su trabajo de escritura hasta que el amanecer nos muestra el escritorio con el poema ya terminado -junto con las redacciones previas desechadas-, y la vela consumida. La ausencia del poeta es signo igualmente de que el trabajo de escritura ya ha concluido y es el momento en que ya está listo para producir su efecto: Lara se acerca al escritorio, coge el poema y lo lee emocionada.

No debe olvidarse que la función de la poesía en el relato cinematográfico es la de sublimar la relación amorosa de los protagonistas. De ahí la emoción, casi angustiosa, de la lectura que lleva a cabo Lara del poema que lleva su nombre, acompañada en la banda sonora por el tema de Lara de Maurice Jarré en todo su esplendor orquestal. Al terminar, Lara le dice a Zhivago: «Ésa no soy yo, Yuri». «Sí lo eres», responde él. «No. Eres tú», replica ella. Zhivago señala entonces el título del poema, y ella lo lee en voz alta mientras le coge de la mano: «Lara». El poema cumple la función de unir a los dos amantes en una sola individualidad en la que ambos se reconocen: el texto es a la vez Yuri y Lara, unidos por el poder de la poesía en una sola entidad que remite al mito platónico del andrógino (Banquete, 189d-193d).

Como ya señalé antes, no hay en el epílogo de la novela ningún poema que nombre de forma explícita a Lara, menos aún en su título. La mirada poética de Zhivago es para Pasternak mucho más amplia que la que le concede Lean. Hay que reconocer, de todas formas, que la novela en que se basa el filme tiene un espacio mucho mayor -más de setecientas páginas- para poder incluir todo tipo de digresiones sobre la creación literaria, mientras que Lean hubo de ceñirse únicamente a los episodios más importantes de la trama para atender a lo único que podía expresarse dramáticamente, esto es, la historia de amor de los protagonistas. No obstante, el director supo aprovechar el poder simbólico de la imagen -el palacete nevado, la llama de la vela-para sugerir, a su manera y con sus propios objetivos, que la condición de poeta de Zhivago tiene un peso real en el relato, brillantemente 
resumido en la mirada que dirige Lara, en la excepcional actuación de Julie Christie, sobre el poema que lleva su nombre.

\section{IMÁGENES}

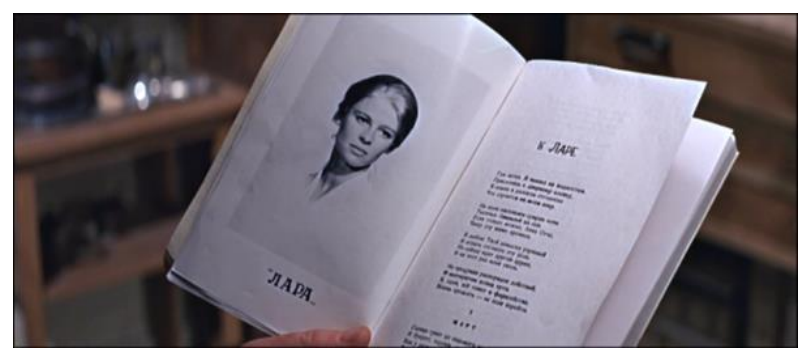

Fot. 1

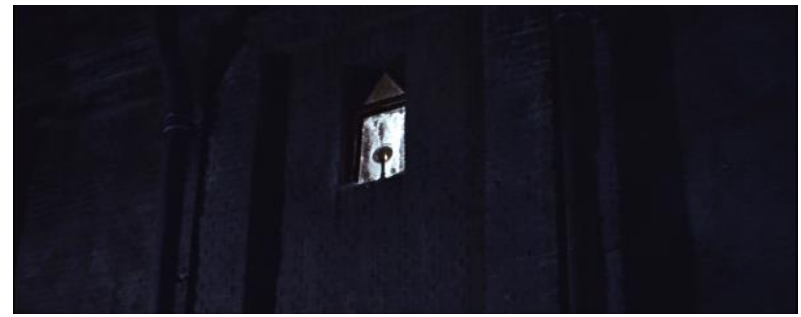

Fot. 2

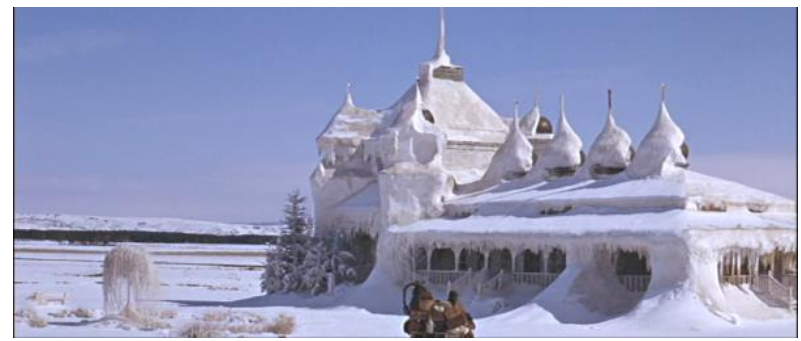

Fot. 3 


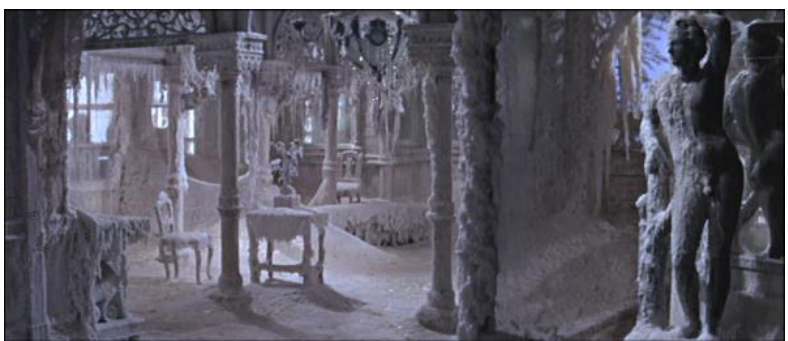

Fot. 4

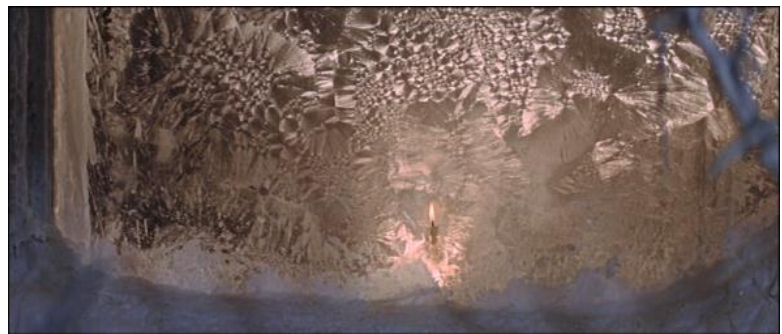

Fot. 5

\section{BIBLIOGRAFÍA CITADA}

Aparicio, José (2008), «Borís Pasternak y Doctor Zhivago», en J. Angulo, R. Cueto y A. Santamarina (coords.), David Lean, San Sebastián, E. P. E. Donostia Kultura, págs. 86-93.

BACHELARD, Gaston (1961), La llama de una vela, trad. de Carlos Schilling, Buenos Aires, El cuenco de plata, 2015.

Benson, Scott (1995), Doctor Zhivago. The Making of a Russian Epic,

Turner Home Entertaiment [documental].

ERLICH, Victor (1959), «The Concept of the Poet in Pasternak», The

Slavonic and East European Review, XXXVII/89, págs. 325-335.

Lamont, Rosette A. (1960), «"As a Gift...” Zhivago, the Poet»,

Publications of the Modern Language Association, 75/5, págs. 621-633.

Moreno Cantero, Ramón (1993), David Lean, Madrid, Cátedra.

Moreno Cantero, Ramón (2000), David Lean: Doctor Zhivago, Barcelona-Buenos Aires, Paidós.

PASTERnak, Borís L. (1957), El doctor Zhivago, trad. de Marta Rebón y

Ferran Mateo, Barcelona, Círculo de Lectores/Galaxia Gutenberg, 2010. 
Juan Carlos Pueo

ReEve, F. D. (1960), «Doctor Zhivago: From Prose to Verse», The Kenyon Review, 22/1, págs. 123-136.

Fecha de recepción: 16/03/21.

Fecha de aceptación: 09/05/21. 